\title{
Promoting and recognising excellence in the supervision of research students: an evidence-based framework
}

\author{
Duncan Nulty $^{\mathrm{a} *}$, Margaret Kiley ${ }^{\mathrm{b}}$ and Noel Meyers ${ }^{\mathrm{c}}$ \\ ${ }^{a}$ Griffith Institute for Higher Education, Griffith University, Brisbane, Australia; ${ }^{b}$ Australian \\ National University, Canberra, Australia; ${ }^{C}$ University of Tasmania, Tasmania, Australia
}

(Received 28 January 2008; final version received 3 September 2008)

One issue universities face is the need to demonstrate excellence in postgraduate research supervision at the individual, faculty and university level. While poor supervision might become obvious over time, with grievances, withdrawals and poor completion times and rates, this paper focuses specifically on identifying and demonstrating supervisory excellence. Currently, the amount and range of evidence used to support claims of supervisory excellence tends to be limited, leaving supervisors, faculties and institutions in a position where demonstrating excellence remains difficult. This paper proposes two inter-dependent ideas which, considered together, help to redress this problem. The first is a 'map' for the collection and use of evidence of supervisory excellence. The second is a 'template' for a 'supervisory excellence report'. The 'map' details the organisational elements, uses of data, and data types which can be considered. The 'report' explains one simple and potent way to organise and present these data for multiple purposes. Together they constitute a muchneeded framework for promoting and recognising excellence in the supervision of research students.

AQ1 Keywords:

\section{Introduction}

For many candidates, there is one individual supervisor with whom they predominantly interact during candidature and might refer to as 'my' supervisor. Perhaps unsurprisingly, the intense intellectual connection and partnership in the student's career development and approaches to research becomes an intensely personal one.

However, that candidate and supervisor operate within a much larger formal and informal research education environment. For example, co-supervisors, advisers, language and skills support staff, librarians, IT and other technical staff, and peers also contribute to the students' development. Effective supervisors see themselves as important members of what can be an extended, and often extensive, team providing education and research support (Kiley 2005). As such, supervisors form a focal point for these diverse contributions to ensure their students become increasingly independent researchers. Similarly, excellent supervisors ensure the student develops increasing alignment between their practice and the research methodologies and approaches of the discipline. In this paper, we are locating the supervisor within this larger context of research supervision.

*Corresponding author: Email: d.nulty@griffith.edu.au 
The student/supervisory team(s)' relationship occurs within a context extending to the National and Institutional levels. For example, Manathunga (2005a, 219) reported that 'government intervention in research higher degree policy across the globe has sharpened universities' focus on the quality of their students' research education experience and on timely completion rates'. Concurrently, research intensive universities have focused increasing attention on enriching supervisory excellence as one tool to enhance research students' publication activity. In both cases, greater emphasis on excellent supervision requires a mechanism to demonstrate the outcomes of such practices at the individual, faculty and university level (Manathunga 2005a, 2005b). Currently, the amount and range

10 of evidence used to support claims of supervisory excellence remains limited. The absence of such tools leaves supervisors, faculties and institutions in a position where demonstrating excellence proves challenging (Aspland et al. 1999; Marsh 2002; Trigwell and DunbarGoddet 2005).

The level of difficulty associated with evidencing supervisory excellence is partly attributable to the variety of supervisory roles that exist and contribute to a candidate's research degree completion. Examples of this variety have been described by Taylor and Beasley (2005) and Pearson and Kayrooz (2004). Their work will be elaborated later in this paper. Another difficulty is the nature of supervision. For example, a number of authors argue that effective supervision is a form of mentoring (Pearson 2001; Pearson and Brew 20 2002; Price and Money 2002; Wisker 2005). Manathunga (2007) describes supervisory behaviour consistent with this understanding in the following way:

[Supervisors] ... guide and facilitate their students' gradual development into independent researchers through empathetic dialogue and by modelling appropriate disciplinary-based research behaviour.

And, citing Pearson and Brew (2002) continues:

They socialize students into disciplinary research cultures, provide emotional support, and assist with broader career development.

An even more explicit elucidation of what the mentoring concept of supervision involves is provided by an analysis of 350 applications for the Nature Mentors' Award, conducted by the journal Nature (Lee, Carina, and Campbell 2007). Among a broad range of characteristics of good mentors, these authors list enthusiasm, passion, sensitiv35 ity, respect, unselfishness, appreciating individual differences, and balancing direction and self-direction. Clearly, with behaviours and characteristics of these kinds it is a challenge to capture evidence illustrating good practice. However, interestingly, students recognise in excellent undergraduate teachers these same traits (Marsh 1987; Prosser and Trigwell 1998). Such recognition raises the prospect that approaches used to capture 40 evidence of teaching effectiveness could also apply to gathering evidence of excellent research supervision.

An indication of the magnitude of the challenge associated with specifying a framework to collect evidence and guide research supervisory practice can be obtained through examination of the research literature. Such an examination reveals the diverse and multifaceted evidence that could be used to demonstrate supervisory effectiveness. For example, a number of studies seek the candidate perspective about the quality of supervision and the various practices and roles in which supervisors engage. In one of these, Heath (2002) surveyed $355 \mathrm{PhD}$ candidates at the time of thesis submission and found that $85 \%$ of respondents were satisfied with supervision - thus leaving $15 \%$ who were dissatisfied 
(41). Other studies draw a link between supervision, student progression and completion. For example, Latona and Browne (2001) and Sinclair (2004) identify a link between supervisory style, the percentage of candidates completing and the time taken to complete. Other research addresses supervisory style and the pedagogy of research supervision. For example, Boud and Costley (forthcoming), Pearson and Brew (2002), Gatfield (2005) and Wisker (2005) all point to the complexity of the supervisory relationship and the need for the supervisor to have a range of approaches and skills. Finally, Cullen et al. (1994) and Neumann (2003) address institutional issues of research supervision and the importance of quality supervision.

We can examine these dimensions of the research supervision relationship from the perspective of supervisor and candidate, respectively.

\section{Characterising postgraduate supervisory excellence: the supervisor's perspective}

Excellent research supervisors will likely have achieved broad experience across a number of supervisory contexts and roles. Such supervisory roles could include, but not be limited to, one-to-one supervision of Honours, Masters and Doctoral students as either a principal or co-supervisor. Co-supervisory arrangements may also sometimes be used. However, significant variation occurs in the formulation and operation of these arrangements. Sometimes there may be just one other 'associate supervisor'. The principal supervisor may see this person rarely if ever. Despite that, the principal supervisor may know (through discussion with the student) that the associate supervisor supplies very different, complementary, support. Alternatively, there might be times when co-supervision is characterised by joint supervisory meetings. Experienced supervisors will have been the 'principal' supervisor for some students, the 'associate' for others.

Some institutions implement supervisory teams that build on the strengths and experience of supervisors to enrich the supervisory capability of early career academics. The experienced academic may oversee the supervision of the candidate without actually supervising them, instead acting as a mentor to the team. When a supervisor has gained substantial supervisory experience, it is more likely that they will have acted in this role. It is possible that such a role is a potent way to enrich supervisory practice.

Irrespective of the model adopted, supervision would support each individual's progression through their own learning journey. Such supervision would comprise a dynamic approach which would alter as the students' needs changed throughout the candidature of each (Wright 1992). It follows that the supervisor's ability to be flexible and to adaptively facilitate the process is one of the hallmarks of supervisory excellence. For example, Manathunga (2005a) noted that effective supervisors remain vigilant for, and then act on, cues indicating their students may be experiencing some difficulty. Such attentive supervisors would adaptively engage a range of strategies to facilitate students' ongoing progression.

Good supervisors know how to adopt different supervisory practices dependent on the students' needs, their progress through their candidature, and the nature of the relationships they have had with others involved in the supervisory process. Highly successful supervisors tailor their approaches to guiding individuals, rather than adopting a one-size-fits-all model. With practice, and a variety of experiences, the capabilities of a supervisor has to do this can be expected to grow. As such, experience, an ongoing professional commitment to development, and engagement with reflective and reflexive practice, all represent hallmarks of excellence (Lee, Carina, and Campbell 2007). Evidence of such attributes represents one aspect of the supervisory relationship. The students' perspective represents the other equally 
important contribution necessary to inform the development of a framework to evaluate supervisory excellence.

\section{Characterising postgraduate supervision excellence: the candidate's perspective}

Gurr (2001) alludes to the profound influence students' experience of supervision has on their approach to research. Discussions with experienced supervisors demonstrate that early in their career they will likely either adopt or modify the supervision model they experienced, or enact their own approach diametrically opposed to their own experiences. The models of supervision that produce these orientations to supervision come in various forms. For example, what might be called a 'traditional' style occurs when there is 'an intense, individual relationship between a research supervisor (master/guru) and a research student (protégé/disciple)' (Frow 1988; Giblett 1992; Threadgold 1995; Yeatman 1995; Grant 2001) cited by Manathunga (2005a).

Pearson and Kayrooz (2004) provide a useful model for thinking about reflecting on and delivering richer and more structured supervisory experiences to students. Their model includes four roles: Mentoring, Sponsoring, Progressing the candidature and Coaching.

A 'mentor' is often referred to by many successful researchers as someone who was significant in their career. The mentoring role requires specific subject expertise and includes mentoring students so they can complete the research project itself, but also mentoring the intellectual development of the student, i.e. the mentor encourages publishing; encourages networking; helps with seminar and conference presentations; and assists with career goals.

A 'sponsor' can assist with funding and the identification and provision of resources. The sponsor is one who, for example, will: make sure that new candidates have access to basic resources such as desk, phone and computer; ensure, or advise how students can access funding for conferences, field work and workshops; identify administrative procedures that students need to meet and who assists in achieving these in a timely manner; introduces the student to professional and discipline networks; and gives candidates access to expertise and full participation in the research 'practice'. This includes directing students to alternative sources of expertise.

The 'progressing the candidature' role can be thought of as facilitation-related functions, these include: monitoring progress; periodically reviewing supervision arrangements; negotiating availability and initiating contact; and devoting sufficient time to the student. This last point remains so important, that it warrants scrutiny and expansion. In the context of this paper, we define this role as providing guidance on the thinking processes that lead to successful research outcomes. In this sense, the supervisor will provide opportunities for the student to expand their thinking approaches. Concurrently, through effective guidance, the supervisor assists in enriching the student's intellectual flexibility in thinking about and conceiving not only how to solve problems, but to conceive of those problems in the first place.

A supervisor in the 'coach' role involves helping candidates develop their research expertise while they are actually doing their research project. The coaching role is often performed by a range of people with varying expertise such as other academics and students, technical staff and other professionals e.g. librarians and statistical consultants. The coach role includes: establishing the coaching partnership, action planning (Zeus and Skffington 2001, 60) such as helping students with identifying the research question and theoretical framework; helping plan and refine the project; advising on critical aspects of research; being directive when needed, and continually evaluating and following up 
areas of the relationship in which improvements can be achieved (Zeus and Skffington 2001, 79).

\section{Dimensions of supervision}

Three dimensions characterise the contribution of a supervisor. The first is the nature of the 'group' supervised. The second is the 'role' of the supervisor. The third is whether the supervisor works alone, with another, or in a team, as principal or associate, leader or team member. For simplicity, the first two dimensions are used in Table 1 to form a grid to help summarise different supervisory situations.

Using only the two dimensions represented in the grid (temporarily ignoring the third i.e. individual supervision or supervision with others) identifies 12 different supervisory scenarios. When the third dimension is added, we may imagine this table reproduced three times: first, where a supervisor works alone (increasingly this arrangement has become the exception, but we include it here for completeness); second, where the supervisor works with another in a co-supervisory relationship; and third, where the supervisor is working in a supervisory team, either as principal or associate, leader or simply team member. Doing this results in 36 qualitatively different possible supervisory situations.

To this diversity should be added the realisation that a supervisory situation is not static, but rather dynamic. This implies that only in some rare cases of supervision will the character of supervision be consistent with only one role throughout a student's candidature. It would be more usual to expect the supervisory role to change over time - perhaps several times. In this sense, the relationship would be dynamic, developmental and would change progressively with the increasing intellectual maturation of the candidate. The dynamic nature of postgraduate supervision is therefore a fourth dimension to be considered, and it is this, in part, which makes supervision so multi-faceted, complex and demanding (Armstrong and Conrad 1995, 180).

In conclusion, postgraduate supervision is not a single activity done in the same way every time. What works in one situation may work less successfully in another. Good practice must be sensitive to context, an understanding supported by the work of Cumming (2007).

It follows that to evaluate the effectiveness of postgraduate supervision, different approaches are needed. It is possible, if not likely, that some evaluation approaches may be valid in some scenarios but not valid in others. It also means that demonstrating good supervisory practice is unlikely to be simple.

To guide the practice of supervisors and to inform preparation of a case claiming supervisory excellence, a 'map' for the collection and use of evidence of supervisory excellence is presented. The map is based largely on the growing research literature on research supervision. This is followed by proposing a reporting structure designed to

Table 1. Partial range of different supervisory situations.

\begin{tabular}{|c|c|c|c|c|c|}
\hline & & \multicolumn{4}{|c|}{ Role } \\
\hline & & $\begin{array}{l}\text { Mentor, including } \\
\text { content expert }\end{array}$ & Sponsor & $\begin{array}{l}\text { Progressing the } \\
\text { candidature }\end{array}$ & Coach \\
\hline Group & $\begin{array}{l}1: 1 \text { with candidate } \\
\text { Larger group } \\
\text { Small cohort }\end{array}$ & & & & \\
\hline
\end{tabular}


recognise excellent supervisory practices. Together these form an evidence-based framework for promoting and recognising excellence in the supervision of research students.

\section{A map for evidencing supervisory excellence}

The map is presented diagrammatically in Figure 1. Overall, this illustrates the terrain of evidencing excellence in postgraduate supervision. It includes the different stakeholder groups, the different purposes each stakeholder may have, associated organisational processes, different types of data relating to postgraduate supervision and the relationships among all these elements. The map seeks to clarify the process by which any one stakeholder would gather and use evidence in relation to supervisory practice and, in this way, to act as a guide. What follows is a description of Figure 1.

The first row consists of three different stakeholder 'groups ' in an organisation. These are presented in order of increasing size: the individual supervisor; a school, department or college; and the university as a whole. Any one of these groups can have an interest in demonstrating supervisory excellence. Thus, individual academics (as the smallest 'group') may each wish to demonstrate that they are excellent supervisors. Alternatively, a Head of School/Department or College may seek to demonstrate that the School/Department or College has implemented protocols and procedures that have developed a culture of supervisory excellence. Similarly, an institution may wish to use the map as a basis for recognising excellent current practices. Importantly, such foundation data can focus performance on those areas that will produce the greatest improvements and strategic development of supervisory practices across the institution.

The second row shows the different purposes each of the organisational groups may have when collecting and using data related to the quality of supervisory practice. These are: a formative, developmental purpose; a performance management purpose (which is likely to be a blend of formative and summative activity); and a summative purpose (aimed at demonstrating the level or degree of excellence achieved).

These three purposes relate to quality management processes. Specifically, the formative purpose seeks explicitly to bring about improvements in performance (or at least the maintenance of good performance). As such, it relates to quality enhancement processes. Performance management has a dual role: in part, it aims to assist with formative, developmental actions to improve or maintain performance; in part, it also seeks to impose accountability for performance levels achieved. As such, it relates to quality enhancement and quality assurance processes. The summative purpose seeks only to demonstrate a level of performance - implicitly to assure interested parties of the quality of supervisory practice, and by association perhaps also value for money. As such, it relates to quality assurance. These mappings are, in practice, not as cleanly distinguishable as just implied. The reality is that there is overlap and shades of grey in between. One example would be that an institution is not likely to engage only in quality assurance (as just implied), it would also engage in quality enhancement.

The bottom row of Figure 1 illustrates that different sets of supporting data are relevant depending on the stakeholder group, purpose and associated process. For example, a supervisor seeking to improve their practice is engaged in a quality enhancement process. In this case, data consisting of qualitative feedback from students about supervisory practices may be more useful than data specifying the raw number of students successfully supervised to completion. Conversely, the reverse may be true of an institution seeking to demonstrate the quality of its supervision. Thus, qualitative feedback from students would be one of the items of data included in 'Data Set 1', but would be less likely to be included in 'Data Set 3'. 


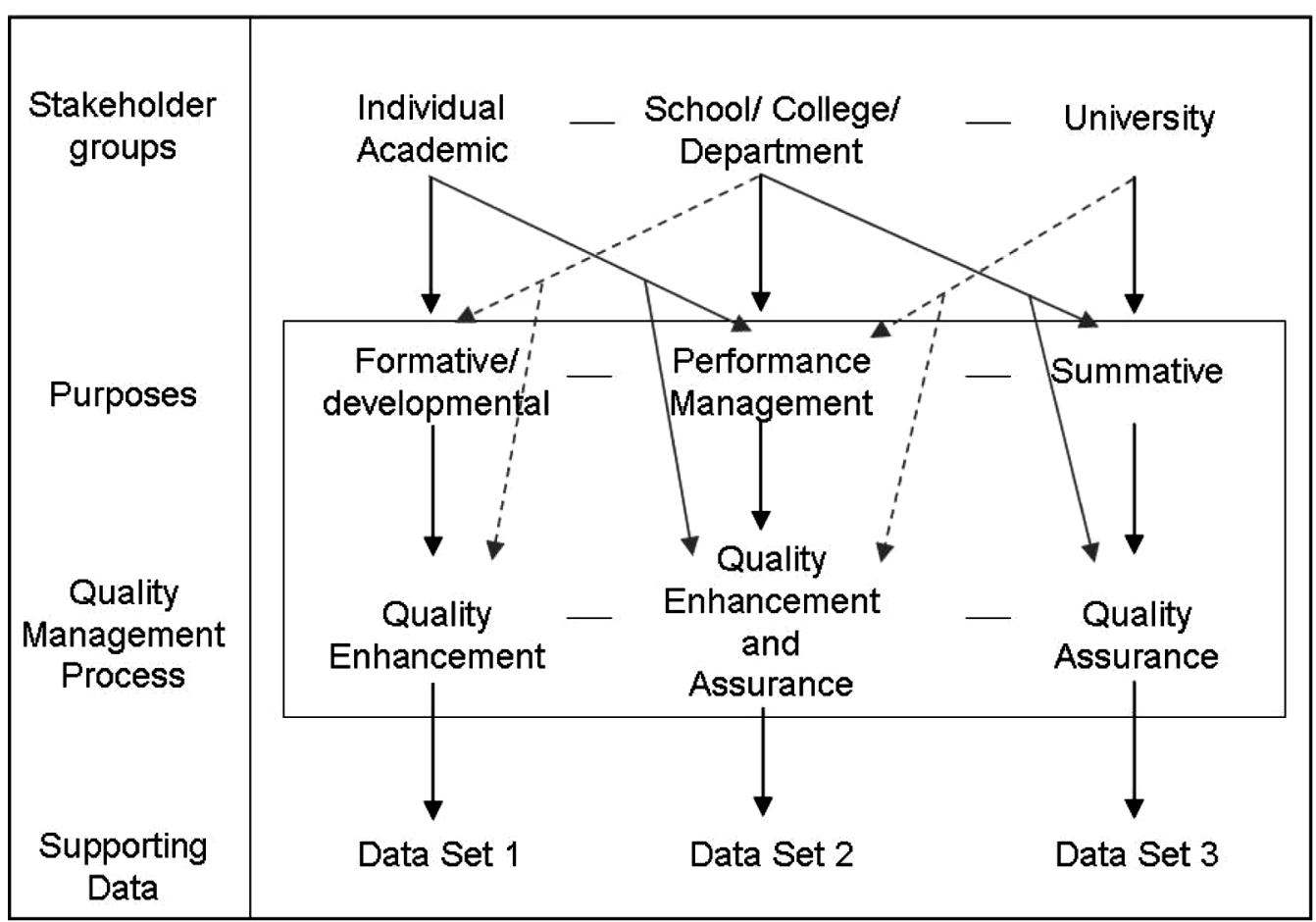

Figure 1. A map for evidencing supervisory excellence.

We say 'less likely' because it is clear that an institution could make use of such data in support of an argument that the quality of supervision it provides is high. However, in the context of quality assurance at the institutional level, qualitative student data are only illustrative of instances of excellence. The argument that such instances are commonplace throughout the institution would need to be supported by reference to other data (such as, for instance, the number of completions per academic and the average time taken).

Between the rows of Figure 1 are arrows of different types to indicate different relationships between the rows. Not every possible relationship is represented by these arrows - the figure is only illustrative. Thus, for example, an individual supervisor could have formative, performance management and summative purposes in mind. Which one takes precedence will depend on the individual's circumstances.

For supervisors who are at an early stage of their career, the most likely concern is to formatively evaluate performance. In Figure 1, a primary relationship is indicated by a solid black arrow - in this case linking the individual to the formative purpose. In turn, formative evaluation links directly to a quality enhancement $(\mathrm{QE})$ process, i.e. these supervisors want to improve their skills as supervisors. It follows that they seek the kind of data that will help them to do so, 'Data Set 1' - to be detailed later.

Secondary interests are indicated by grey arrows. One example is collecting data for performance management purposes - that is to say, supervisors may want to discuss their performance with their boss (we use this colloquialism to avoid confusion between 'postgraduate supervisors' and 'academic supervisors'). Some of the data included in Data Set 1 may be useful here, some will not be. Furthermore, there may be data required which were 
not gathered for the developmental, quality enhancement purpose. Thus, the data needed for performance management purposes are similar to, but different from, the data needed for a solely formative purpose. They are therefore named differently - 'Data Set 2'.

Third (represented by a dashed arrow), supervisors may have an interest in collecting data for summative purposes. That is, there will be circumstances in which supervisors simply want evidence to demonstrate how good their supervision is. Again, some data included in Data Sets 1 and 2 may be useful, but other data will be required. This collection of data is therefore also named differently - 'Data Set 3'.

Similar mappings represented by arrows illustrate the relationships between other organisational groups, purposes, process and datasets. The main point of the diagram is not to get bogged down in the detail of this, but rather to be illustrative of the different linkages between different groups, purposes, processes and data.

\section{Datasets}

The framework described above makes the general point that it is appropriate to use selected data of a kind which are consistent with, and useful for, a particular purpose and associated process. To capture this idea, the framework focuses on specific examples of the data that could be used for a particular purpose. Thus:

Data Set $1 \rightarrow$ Quality Enhancement

Data Set $2 \rightarrow$ Quality Enhancement and Assurance

Data Set $3 \rightarrow$ Quality Assurance

So far as possible, what follows represents a description of the details that could be included in each of the three datasets described.

However, of course, such matters are not simple. In reality, there is not a single linear mapping between data and the use to which it can be put. Rather, the same data can be presented in different ways and used for different purposes. Earlier in this paper, an example was provided where qualitative data (written comments from students) could be used formatively and summatively. Similarly, quantitative data summarising the range of supervisory experience an individual has accumulated could be used, on the one hand, to identify areas in need of development (a formative function). On the other hand, the same data could be used summatively to illustrate that the supervisor has a broad base of experience (despite, perhaps, one area where experience is lacking).

In practice, decisions about the particular way in which a specific type of data will be used is a local and context dependent one. As such, while agreement on the 'most appropriate' use for particular data remains unlikely, agreement on the acceptable types of data

40 to be used as evidence demonstrating excellent practice remains a desirable component of a university's research and learning philosophy. In general, qualitative data are more likely to be useful in a formative sense, while quantitative data are more likely to be useful (and efficient) in a summative sense - but, these uses are not exclusive. Table 2 provides examples of the types of different data sources that could be used to support claims of supervisory excellence, or to develop supervisory excellence, or both. Allocating data sources to particular datasets or purposes is deliberately not attempted. Listing the different sources of data in this way is provided simply as a useful aid to the challenge of determining what sorts of data might be useful when developing a supervisory excellence report. 
Table 2. Datasets.

Data description

Exit interview data of successful and unsuccessful students

Survey data gathered using questionnaires developed by your own institution. For example,

Australian National University has a 'Doctoral Experience Questionnaire' (the ANU-DEQ)

The Australian Government's Postgraduate Research Experience Questionnaire, a survey administered to all Australian doctoral graduates on graduation

Peer evaluation of supervision perhaps including contributions from the Convenor of the Supervisory Panel

Data regarding the entry criteria and academic standard of students

Student testimonials

A supervisory log or diary:

- critically reflective accounts of your practices and ways you have developed your practice over time

- quantitative records of the total volume/load/time spent on supervision

Proxy indicators including:

- examiners' reports

- total supervisory load

- the number of students requesting supervision by a particular supervisor

- progression times and completion rates

Details of procedures used to clarify role expectation and delivery in the supervisory relationship

Extracts from annual progress reports

Case studies/narratives of supervision

Evidence of the scholarship of supervision including:

- publications on supervisory practice

- completion of formal professional development courses

- attendance and/or presentations for supervisory workshops and related conferences

Details of employment outcomes of graduates

Data regarding student publications and/or joint publications derived from the candidature

Data regarding awards and citations given to students and/or supervisors

Extracts from the acknowledgement section of your students' theses

Supervisory Practice Portfolio (a systematic collation - and distillation - of all the evidence you have gathered). [NB: this would incorporate consideration of what you as a supervisor were trying to do, why, informed by literature on good practice, evidence that you were deliberate in your attempts to do it and whether it worked.]

\section{A reporting structure designed to recognise excellent supervisory practices}

Having mapped the relationships between organisational groups, purposes, process and datasets, and having listed some of the kinds of data comprising these datasets, the following section describes a way of reporting. The advantages of this approach are detailed at the end of this section.

What is advocated is that some degree of systematisation and standardisation be provided by specifying a structure for a Supervisory Excellence Report.

In summary, the Supervisory Excellence Report could consist of:

(1) An executive summary (approximately one page)

(2) A report (of about five pages) including:

- context statement;

- supervision philosophy and underpinning theoretical framework;

- selected quantitative data; and

- selected qualitative data. 
(3) Plans for future development as a result of evidence provided (approximately one page).

The Supervisory Excellence Report consists of a collection of evidence of supervisory excellence constructed around a theoretical frame (that the supervisor articulates in a philosophy of supervision statement). In full, it might consist of no more than seven or so pages (plus appendices). While this suggested length is somewhat arbitrary, our suggestion is to keep the document short and succinct in the belief that this will make it more manageable (for the academic producing it) and more useable across multiple potential audiences. Ultimately however, the length is a political decision, informed by the specific purpose to which the report will be put. It is also dependent on the volume of material (evidence) which the author has to draw upon. As such, individuals and institutions need to consider the types of evidence they believe to represent measures that are both valid and reliable, and correspondingly to exercise some discretion and judgement in respect of the length and content of the report. Accordingly, our suggestion is a guide: the principle being for the report to be no longer than it really needs to be.

In more detail:

The first page represents an executive summary, written in a manner that ensures it can stand alone to demonstrate supervisory excellence. In this sense, the executive summary could be considered as a supervisory profile. When submitted together with executive summaries from similarly constructed 'excellence reports' on teaching, research and service, these documents provide career summaries amenable to multiple purposes (such as applications for promotion, awards and/or research grants).

The main body of the report should begin with a 'context statement' which should delineate the scope of the supervisory experience which is being reported (essentially limiting the report to a sub-set of the various possibilities offered by Table 1).

What follows are illustrative examples of the kinds of content which could appear in the different sections of the Supervisory Excellence Report. The approach taken is to consider the developing expertise of an imaginary academic at two points of a 25 -year career in postgraduate supervision. The illustration begins three years into the academic's career, and is examined again at 25 years. In this way, the way changes in the content and its presentation can be seen. (An alternative way to view this illustration is to consider it as two separate individuals, one who is early career, the other late career.)

Beginning with our hypothetical academic just three years into his/her academic career.

I am a new academic (lecturer level) with just under three years' supervisory experience. To date, this has been confined to being an associate supervisor of one, part-time, research masters student, and associate supervisor for one full-time Doctor of Philosophy student. I am also the sole supervisor for two Honours students and two students undertaking a research project as part of their coursework masters programme. Of the research masters students, one has completed and graduated, one is in the final stages of preparing their thesis, the other has completed their first year. The PhD student has just successfully completed her "confirmation of candidature' and is now entering the main data collection phase. The coursework projects are of a semester's length and the Honours projects each of one year in length. Due to my coursework and Honours students, the Department has agreed that my existing supervisory load is equal to the university's stated 'normal supervisory load'.

Note how this context statement changes in response to increased supervisory responsibilities and experience 25 years into this academic's career: 
I am an Associate Professor with 25 years' supervisory experience. This has seen $9 \mathrm{PhD}$ completions, 18 Research Master Completions and 14 Master of Philosophy completions. I am currently supervising four $\mathrm{PhD}$ students (one near completion) and four Masters (all part-time candidates). This supervisory load is above the university's norm, but commensurate with my level of experience and the fact that I am employed in a research-intensive capacity (research load of $60 \%$ ). In addition, I have taught many coursework masters students in cohorts up to 35 students over the past 15 years (current enrolment in the Master of Business Administration totals 55 students over two-year levels). I have held the position of Research Student's Coordinator in my current School for the past six years, and I am a member of the research ethics committee for my discipline. These roles have involved, among other matters, the provision of research supervision training seminars and mentoring of supervisors in supervisory teams. Thus, my supervision extends from one to one research supervision, to group supervision and to mentoring other academics. I also have three relevant journal publications (tier 1 journals) about supervision practices in my discipline.

This should be followed by selected data which, leading logically from the context statement, quantitatively summarise the supervisory experiences reported on. Thus, for example, the data already incorporated into the above examples could be presented (and elaborated) in a tabular form, e.g., at the early career stage the summary could appear as given in Table 3 .

By later career, our hypothetical academic would be more likely to present aggregated summary data instead of a 'student-by-student' account. In addition, this academic could draw on a particularly broad range of quantitative data. Such data would likely include information on completion rates, data on awards for graduates, student satisfaction ratings (e.g. deriving from their MBA supervision) and so on (drawing on relevant sources listed in Table 2).

PhD student completions

Five with an average time to completion of 4 years (Full-time Equivalent - FTE) Two with an average time to completion of 4.6 years (FTE)

Average for Discipline $=4.2$

Table 3. Summary of research supervision to date.

\begin{tabular}{|c|c|c|c|c|}
\hline Level & Commenced & Candidature & Supervisory role and load & Status \\
\hline Masters & 2006, Semester 1 & Part-time & Associate supervisor $(40 \%)$ & $\begin{array}{l}\text { Completed (2008) } \\
\text { (On time) }\end{array}$ \\
\hline Masters & 2006, Semester 1 & Part-time & Principal supervisor $(70 \%)$ & $\begin{array}{l}\text { Final write-up Submit } \\
\text { 2008, S2 }\end{array}$ \\
\hline Masters & 2007, Semester 1 & Part-time & Principal supervisor $(70 \%)$ & $\begin{array}{l}\text { Data analysis Submit } \\
\text { 2009, S1 }\end{array}$ \\
\hline $\mathrm{PhD}$ & 2007, Semester 1 & Part-time & Associate supervisor $(70 \%)$ & $\begin{array}{l}\text { Data analysis. Submit } \\
\text { expect (2009). }\end{array}$ \\
\hline Honours & 2008, Semester 1 & Full-time & $100 \%$ & $\begin{array}{l}\text { Submission expected } \\
\text { November } 2008\end{array}$ \\
\hline Honours & 2008, Semester 1 & Full-time & $100 \%$ & $\begin{array}{l}\text { Submission expected } \\
\text { November } 2008\end{array}$ \\
\hline $\begin{array}{l}\text { Coursework } \\
\text { Masters }\end{array}$ & Semester 12008 & Part-time & $100 \%$ & $\begin{array}{l}\text { Due to a short-term } \\
\text { placement overseas } \\
\text { student has taken } \\
\text { leave for } 12 \text { months }\end{array}$ \\
\hline $\begin{array}{l}\text { Coursework } \\
\text { Masters }\end{array}$ & Semester 22008 & Full-time & $100 \%$ & $\begin{array}{l}\text { Due to complete at the } \\
\text { end of the semester }\end{array}$ \\
\hline
\end{tabular}


Examiners' reports across the three examiners

$\begin{array}{llll}\text { Three candidates } & \begin{array}{l}\text { Examiner 1 } \\ \text { Accept without } \\ \text { change }\end{array} & \begin{array}{l}\text { Examiner 2 } \\ \text { Accept without } \\ \text { change }\end{array} & \begin{array}{l}\text { Examiner 3 } \\ \text { Accept without } \\ \text { change }\end{array} \\ \text { Five candidates } & \begin{array}{l}\text { Accept with minor } \\ \text { changes }\end{array} & \begin{array}{l}\text { Accept with } \\ \text { minor changes }\end{array} \\ \text { One candidates } & \begin{array}{l}\text { Accept with minor } \\ \text { changes }\end{array} & \begin{array}{l}\text { Accept with minor } \\ \text { changes }\end{array} & \begin{array}{l}\text { Accept with } \\ \text { minor changes }\end{array} \\ \text { Departmental } & \begin{array}{l}\text { Accept with minor } \\ \text { average }\end{array} & \begin{array}{l}\text { Accept with minor } \\ \text { changes }\end{array} & \begin{array}{l}\text { Accept with } \\ \text { minor changes }\end{array}\end{array}$

The third section should also present selected data, but of a more qualitative kind. These data would be used to demonstrate how the academic enacts their supervisory philosophy in practice and the outcomes students achieve in consequence. Raw data, if appropriate, would only be included as appendices. This section is meant to provide the author with the opportunity to 'tell their story' in concise and readable prose. This scholarly section provides the academic with opportunity to explain how the quantitative summary in the previous section illustrates their qualitatively excellent supervisory practices, preferably incorporating some theoretically justified statements with evidence to support them. For example:

Of my nine PhD students, I take pride in the fact that seven completed within the university's average of 4.2 years for my discipline. Of the two who took, on average, six months longer, one gave birth to her first child and the other, an older student, had her invalid father come to live with her toward the end of candidature, hence slowing her progress.

Again, of my nine $\mathrm{PhD}$ completions the examination record compares very favourably with the average across the department. I consider one of the main reasons my students achieve success relates to how I enact my supervision philosophy. I pay particular attention to, and work closely with, my students in the first 9-12 months of their candidature. In particular, I focus on mentoring their project development, modelling the thought and research processes, and guiding my students' critical self-reflection into their developing research epistemologies. Equally, through his process, I ensure my students have achieved a sound grounding in the understanding and skills they will need to complete their project by, or within, our agreed timelines.

Finally, in the light of what the report demonstrates, plans for future development should be presented. For example, for our early career academic:

As an early career academic, I recognise that I want to broaden the range of postgraduate research supervision I engage in, as well as to simply accumulate more experience. In part, I know this will just take time. However, to support the development of my expertise in the process of supervising students, I have committed myself to participate this year in a series of professional development workshops organised by the University's 'Office for Research' in collaboration with its Academic Development Unit. I also aim to avail myself of some mentoring support. To this end I have, on the advice of the chair of the school Research Committee, undertaken some co-supervisory meetings with my students together with a more experienced colleague (who is the associate supervisor). I have negotiated for this person to provide me with some specific peer evaluation of my supervision. This involves discussion based on my entries in a reflective supervisory diary, and records of direct-structured observations of my supervision by my colleague. There is the added possibility that this approach may result in publications that draw on our experiences and the data we are gathering.

This simple structure allows the systematic inclusion of all the different data types listed in the previous section. At the same time, it takes account of the supervisory context and 
focuses the report on evidence-based analysis rather than uncritical and/or unstructured assertion. It is a structure which can be adopted regardless of context or available data. As such, it offers standardisation which is both helpful to those preparing such reports and to those who read them. Its cumulative structure means that either the first page alone, the body of the document, or the full document including appendices, can be used depending on the particular purpose.

\section{Summary and conclusion}

This paper outlines four dimensions of supervisory practice. It then presents a 'map' of the terrain for evidencing supervisory excellence. Next, it lists some of the types of evidence that can be collected in relation to supervisory practice. The paper finishes with a suggested reporting model for the systematic and strategic presentation of these data. This section includes some examples. Inevitably, this is limited by space in this paper, but they do begin to illustrate what each section of the report could contain, and its expected flavour. Considered together these components form an evidence-based framework for promoting and recognising excellence in the supervision of research students. The importance of this framework lies in the structured collection of evidence in support of claims of excellent research supervisory practices. This framework will support practice, reflection and development of evidence-based claims of supervisory excellence. Such a framework has application at the level of individual academics, schools, faculties and institutions. The framework demonstrates the interconnected nature of each of the four dimensions of supervisory practice. Evidence collected under each dimension also serves to focus attention on the interconnections between the dimensions. Importantly, the framework provides a categorised, systematic approach to collecting and reflecting on the range of data that can support claims of supervisory excellence.

\section{Notes on contributors}

Duncan Nulty is a Senior Lecturer in the Griffith Institute for Higher Education at Griffith University, Queensland, Australia. He has more than a decade of experience in teaching, course and programme evaluation obtained in several large universities. He has also conducted many educational evaluation consultancies in Australia and overseas.

\section{References}

Armstrong, J., and L. Conrad. 1995. Subject evaluation: A resource book for improving teaching and learning. Brisbane: Griffith Institute for Higher Education, Griffith University.

Aspland, T., H. Edwards, J. O’Leary, and Y. Ryan. 1999. Tracking new directions in the evaluation of postgraduate supervision. Innovative Higher Education 24, no. 2: 127.

Boud, D., and C. Costley. Forthcoming. From project supervision to advising: New conceptions of

AQ4 the practice. Innovations in Education and Teaching International.
Cullen, D., M. Pearson, L. Saha, and R. Spear. 1994. Establishing effective PhD supervision. Canberra: Higher Education Division, DEET.

Cumming, J. 2007. Using narrative, interpretation and reflexivity to reconceptualise the doctoral experience. Paper presented at the American Education Research Association Conference, April, in Chicago, IL.

Frow, J. 1988. Discipline and disciplineship. Textual Practice 2: 307-23.

Gatfield, T. 2005. An investigation into PhD supervisory management styles: Development of a dynamic conceptual model and its managerial implications. Journal of Higher Education Policy and Management 27, no. 3: 311-25.

Giblett, R. 1992. The desire for disciples. Paragraph 15: 136-55. 
Grant, B. 2001. Dirty work: 'A code for supervision' read against the grain. In Postgraduate research supervision: Transforming (R)elations, ed. A. Bartlett and G. Mercer, 13-24. New York: Peter Lang.

Gurr, G.M. 2001. Negotiating the 'rackety bridge' - Dynamic model for aligning supervisory style with research student development. Higher Education Research and Development 21, no. 1: $81-92$.

Heath, T. 2002. A quantitative analysis of PhD students' views of supervision. Higher Education Research and Development 21, no. 1: 41-53.

Kiley, M. 2005. Framework for research supervision support and development at the Australian National University. http://www.anu.edu.au/cedam/anuonly/researchsuper/PDFs/ anu_framework.pdf (accessed October 22, 2007).

Latona, K., and M. Browne. 2001. Factors associated with completion of research higher degrees (Higher Education Series). Canberra: DETYA, Higher Education Division.

Lee, A., D. Carina, and P. Campbell. 2007. Nature's guide for mentors. Nature 447: 791-7.

Manathunga, C. 2005a. Early warning signs in postgraduate research education: A different approach to timely completions. Teaching in Higher Education 10, no. 2: 219-33. International Journal for Academic Development 10, no. 1: 17-30.

. 2007. Supervision as mentoring: The role of power and boundary crossing. Studies in Continuing Education 29, no. 2: 207-21.

Marsh, H.W. 1987. Students' evaluations of university teaching: Research findings, methodological issues, and directions for future research. International Journal of Educational Research 11: $253-388$. . 2002. PhD students' evaluations of research supervision. Journal of Higher Education 73, no. 3 : $313-48$.

Neumann, R. 2003. The doctoral education experience (Evaluations and Investigations Programme). Canberra: Department of Education Science and Training.

Pearson, M. 2001. Research supervision - Mystery and mastery. In Practice knowledge and expertise in the health professions, ed. J. Higgs and A. Titchen. Oxford: Butterworth-Heinemann.

Pearson, M., and A. Brew. 2002. Research training and supervision development. Studies in Higher Education 27, no. 2: 135-50.

Pearson, M., and C. Kayrooz. 2004. Enabling critical reflection on research supervisory practice. International Journal for Academic Development 9, no. 1: 99-116.

Price, D., and A. Money. 2002. Alternative models for doctoral mentor organisation and research supervision. Mentoring and Tutoring 10, no. 2: 127-36.

Prosser, M., and K. Trigwell. 1998. Teaching for learning in higher education. Buckingham: Open University Press.

Sinclair, M. 2004. The pedagogy of 'good' PhD supervision: A national cross-disciplinary investigation of PhD supervision. Canberra: Commonwealth of Australia.

Taylor, S., and N. Beasley. 2005. A handbook for doctoral supervisors. London: RoutledgeFalmer.

Threadgold, T. 1995. Pedagogy, psychoanalysis, feminism: Review of the book 'Jane Gallop seminar papers'. Australian Universities Review 38, no. 2: 46-8.

Trigwell, K., and H. Dunbar-Goddet. 2005. The research experience of postgraduate research students at the University of Oxford. Oxford: University of Oxford.

Wisker, G. 2005. The good supervisor: Supervising postgraduate and undergraduate research for doctoral theses and dissertations. Basingstoke: Palgrave Macmillan.

Wright, J. 1992. Effective supervision: The key to satisfactory completion rates. In Starting research - Supervision and training, ed. O. Zuber-Skerritt. Brisbane: Tertiary Education Institute.

Yeatman, A. 1995. Making supervision relationship accountable: Graduate student logs. Australian Universities Review 38, no. 2: 9-11.

Zeus, P., and S. Skffington. 2001. The coaching at work toolkit: A complete guide to techniques and practices. Sydney: McGraw-Hill. 